\title{
Interdisciplinary Medical Product Development Senior Capstone Design
}

\section{Dr. Miiri Kotche, University of Illinois, Chicago}

Miiri Kotche is a Clinical Associate Professor of Bioengineering at the University of Illinois at Chicago, and currently serves as Director of the Medical Accelerator for Devices Laboratory (MAD Lab) at the UIC Innovation Center. Prior to joining the faculty at UIC, she worked in new product development for medical devices, telecommunications and consumer products. She co-teaches both bioengineering capstone design courses, including the longstanding core senior design sequence and the recently launched interdisciplinary medical product development course. She also serves as Director of the Freshman Engineering Success Program, and is actively involved in engineering outreach for global health. Miiri received her $\mathrm{Ph} . D$. in Bioengineering and M.S. in Mechanical Engineering from the University of Illinois at Chicago and a B.S. in General Engineering from the University of Illinois at Urbana Champaign.

\section{Prof. Stephanie Tharp, University of Michigan}

Stephanie Tharp received a master of industrial design degree from the Rhode Island School of Design, and a bachelor of mechanical engineering from the University of Michigan. From 2002 until 2014, she was Associate Professor, and Program Chair, of Industrial Design at the University of Illinois at Chicago's School of Design. She is currently an Associate Professor in the Stamps School of Art \& Design at the University of Michigan. She has work experience with Ford Motor Company, the Massachusetts Institute of Technology, Armstrong Industries, and amazon.com.

With her husband, Bruce, Stephanie presently runs Materious, a design studio that produces discursive and speculative products. They are currently working on a book, Design as Discourse, which seeks to further legitimize and problematize alternate forms of design practice that extend designers' cultural agency.

Tharp has exhibited her work nationally and internationally and is the recipient of several design awards including Future Furniture Competition Winner from Interior Design Magazine, and Best in Show from Design Within Reach's Modern+Design+Function Chicago Furniture Now Competition. She has lectured and presented nationally and internationally, and has received grants from Motorola, The Consortium to Lower Obesity in Chicago Children, and the OVCR Arts, Architecture and Humanities Award at The University of Illinois at Chicago. 


\title{
Interdisciplinary Medical Product Development Senior Capstone Design
}

\begin{abstract}
Interdisciplinary Medical Product Development (IMPD) is a two-semester capstone senior design course involving students and faculty from multiple disciplines - Bioengineering, Industrial Design, Marketing, Graphic Design, and Medicine. IMPD focuses on applying a usercentered approach to the design of medical devices for the health care sector, and has the following student goals: be able to effectively work on interdisciplinary teams and better understand how other disciplines work and think, develop processes and framework to progress from abstract, high-level problem statements to specific, concrete design prototypes, and learn to effectively communicate to client-partners through oral presentations and written documentation.

While team-based product design is part of the curriculum, formal and sustained interaction with end users to inform the design process is an integral of the Interdisciplinary Product Development capstone courses. The department of Bioengineering is jointly within both the College of Engineering and the College of Medicine, which facilitates student exposure to a wide variety of clinical environments with medical faculty engagement. The course is sponsored by an industry partner, who, in conjunction with faculty, provides project statements that are of strategic business interest. For this reason, all students participate under a Non-Disclosure Agreement. The first semester focuses on early front-end development, including framing the problem, human-centered design research methods in a clinical environment, and ideation. The second semester focuses on development of design criteria, concept refinement, receiving evaluative feedback from the various stakeholders (clinicians, client, end-users), and prototyping.
\end{abstract}

The IMPD course challenges students to understand the "fuzzy front end" of design, verify they are developing solutions that will satisfy an unmet need, and experience the iterative nature of engineering design. This opportunity to work on a "real-world" problem in an interdisciplinary team presents challenges that include both logistic and pedagogical. In the third year offering this alternative to the more traditional bioengineering senior design course, there have been numerous enhancements to the process, including an NIH-funded Clinical Immersion summer program to provide bioengineering students an opportunity to better understand clinical needs and inclusion of medical students on teams to improve clinical feedback throughout the development process. This paper discusses the course structure, evolution, and rationale for the course.

\section{INTRODUCTION}

Team-based design is an essential component of the American engineering undergraduate curriculum, particularly in senior design capstone courses. In the traditional senior design course at the University of Illinois at Chicago (UIC) a problem is presented as a technical challenge for which the teams must navigate and design a solution. The teams will usually work to define the problem, identify the requirements and constraints, propose solutions, and create a product or process to satisfy the requirements. A variation on the traditional team-based senior capstone course sequence at UIC has been introduced for bioengineering students. 
Interdisciplinary Product Development (IPD) programs have been around since the 1990s [1]. Some well-known and well-established IPD programs include Carnegie Mellon University's Master of Integrated Innovation (formerly called Master of Product Development), Stanford's Dschool, and RISD and MIT's collaborative Product Design and Development Studio. In 2002, the University of Illinois at Chicago was among some of the earliest to offer an interdisciplinary product development program, engaging business, design and engineering. Corporate partners sponsor a section of the course, and, with faculty, design project statements that are both of strategic interest and educationally appropriate for a senior design capstone course sequence.

Multidisciplinary and interdisciplinary product development courses are increasingly being offered at more institutions, with the motivation being that they better reflect real-world product design processes, and that considerations outside of a single discipline influence a successful end product $[2,3]$. Interdisciplinary programs offer unique experiences for students that contribute to their personal and professional development through building their capacity to: work closely and collaboratively to better understand how other disciplines work and think, present ideas together to high-level management, and change the way they approach design by framing and solving complex design problems in unique and different ways.

Nationally, while there are a number of IPD programs, there are few interdisciplinary courses that focus specifically on the design of medical devices for the health care sector that the authors are aware of [4-5], and none known involve the mix of disciplines working together at UIC (bioengineering, business, graphic design, industrial design, medicine, design strategy). At UIC, there is excellent access to the medical campus due to the Department of Bioengineering's relationship with the College of Medicine (jointly within Colleges of Medicine and Engineering). Additionally, the UIC Innovation Center offers a neutral space where all of these disciplines can come together on equal footing. We believe this is an important facet of an interdisciplinary course in that no single department has primary ownership of the course. In Fall 2012, the program was launched in the Department of Bioengineering as Interdisciplinary Medical Product Development (IMPD), with cross-listed course offerings to include Industrial Design (both graduate and undergraduates) and Business (undergraduates and MBA students). In Fall 2013, the program was expanded to include Graphic Design students, and in Fall 2014, medical students were added to the program.

Students entering the medical device industry are often limited in industry skill sets and the practice of integrated product development from the early "fuzzy front end" through prototyping. In medical device design, the FDA has increasingly emphasized the importance of identifying user needs, usability, and ergonomics, in response to safety issues related to engineering design, failure, and poor user interface, as well as to reduce the time to market by a more efficient product development process [6]. Because of this, Interdisciplinary Medical Product Design (IMPD) at UIC stresses the value of obtaining first-hand feedback from physicians, nurses, technicians, and lay-users in the earliest stages of product conception. In addition, extended exposure to the clinical environment, where medical devices are used, helps provide context to how behaviors, opinions and environment inform the user experience. Primary ethnographic research, including both observations of the users in their natural environment, and direct exchange and interview with the users, is critical to successful design [7-11]. 
Furthermore, ANSI/AAMI Standard HE75 was issued in 2009 (American National Standards Institute/Association for the Advancement of Medical Instrumentation) [12], which focuses on incorporation of user considerations (user feedback for iterative design refinements, environmental considerations, anthropometry, user needs). It is evident that increased attention is being given to "early and often" interaction with end users to enhance the design process of medical devices.

IMPD at UIC is taught with a user-centered approach, and with the following objectives in mind: effectively function on interdisciplinary teams, understanding how other disciplines work and think, teaching students how to work from abstract to more concrete, learning how to frame and solve complex design problems, and learning to make effective and professional presentations to client-partners.

\section{COURSE EVOLUTION}

Interdisciplinary Medical Product Design involves interdisciplinary student teams collaborating to provide solutions to broad problems framed by an industry partner. During the Fall 2012 and Spring 2013 semesters, UIC piloted the IMPD track as an alternative to the traditional design capstone sequence (all seniors in bioengineering, graphic design, and industrial design have twosemester senior design capstone requirements). This course leverages the success of the internationally recognized Interdisciplinary Product Development (IPD) program at UIC, which started in 2002 with students and faculty from industrial design, marketing, and mechanical engineering. While IPD projects typically focus on the consumer market, the focus of IMPD is driven by developing medical devices and solutions for the health care sector. Both IMPD and IPD are offered through the UIC Innovation Center, a collaborative space supported by industry partnerships and three UIC Colleges (College of Architecture, Design and the Arts, College of Business Administration, and the College of Engineering).

IMPD is a two-semester long process of identifying and developing a new product opportunity in the health care sector. Students are placed into interdisciplinary teams of five to eight students, and there are typically five to six teams that are each assigned a different project statement. Each team is partnered with an industry partner mentor with whom they communicate via weekly conference calls or email exchanges, and teams also present progress to the all client partner mentors during the midterm and final of each semester. The course is co-taught by faculty from the Department of Bioengineering, Marketing and the School of Design, who are all present for each class session.

The IMPD course launched in 2012-13 in partnership with CompanyXYZ Healthcare, and had participation from students and faculty in bioengineering (nine seniors and one faculty), business (five MBA students and one faculty), and industrial design (five MFA graduate students, three undergraduate students, and one faculty). The course was taught a second time during 20132014 , and some modifications were made to address deficiencies from the inaugural year. In this offering, there was particular emphasis on: (1) creating more formalized connections to medical campus through establishing better relationships with various departments, including Pediatrics, Family Medicine, and Oncology/Hematology; (2) deepening the user-centered research approach 
by adding a design research and strategy professor to the faculty; (3) including participation of graphic design students, who bring new competencies and different thinking to the process; (4) including a variety of stakeholders who provide clinical feedback throughout the process (the emphasis in the first year was on receiving feedback from only patients). In the current offering of IMPD (2014-15), the teams also include medical students to strengthen the clinical input throughout the design process.

\section{COURSE DESIGN}

\section{A. Planning During the Summer Prior to Course Offering}

Planning begins in early summer with the client partners, faculty, and the Directors of the Interdisciplinary Product Development program and the Innovation Center to properly frame the project statements for the student teams. The problems are designed with guidance and oversight from faculty to address the academic appropriateness of the inquiry to ensure educational outcomes. For the bioengineering curriculum, these stem from ABET student outcomes C, D, E, $\mathrm{G}, \mathrm{H}$, and I. More explicitly:

- C: Ability to design a system, component, or process to meet desired needs within realistic constraints such as economic, environmental, social, political, ethical, health and safety, manufacturability, and sustainability

- D: Ability to function on multi-disciplinary teams

- E: Solve problems

- G: Ability to communicate effectively

- $\mathrm{H}$ : Broad education necessary to understand the impact of engineering solutions in a global and societal context

- I: Recognition of the need for, and an ability to engage in life-long learning

It takes anywhere from several weeks to several months to clarify the project intent, and make sure it serves the needs of both the client and students. The program defines the type of work explored in IMPD as Horizon 2 (Figure 1), which is defined as the next generation of product or service for the company. It depends on growth in an adjacent market and/or deployment of a technology that the company does not currently use. Horizon 1 work is defined by improvements, extensions, and/or cost reduction of existing products (that serve existing markets, that utilize existing technology). Horizon 3 is "blue sky" innovation, which includes exploration into new markets and/or deployment of completely new technologies. The interdisciplinary product development courses at UIC focus on Horizon 2, which provides opportunity for new and innovative approaches to a higher-level problem, yet still necessitates consideration of market positioning, existing patents, and pricing. 


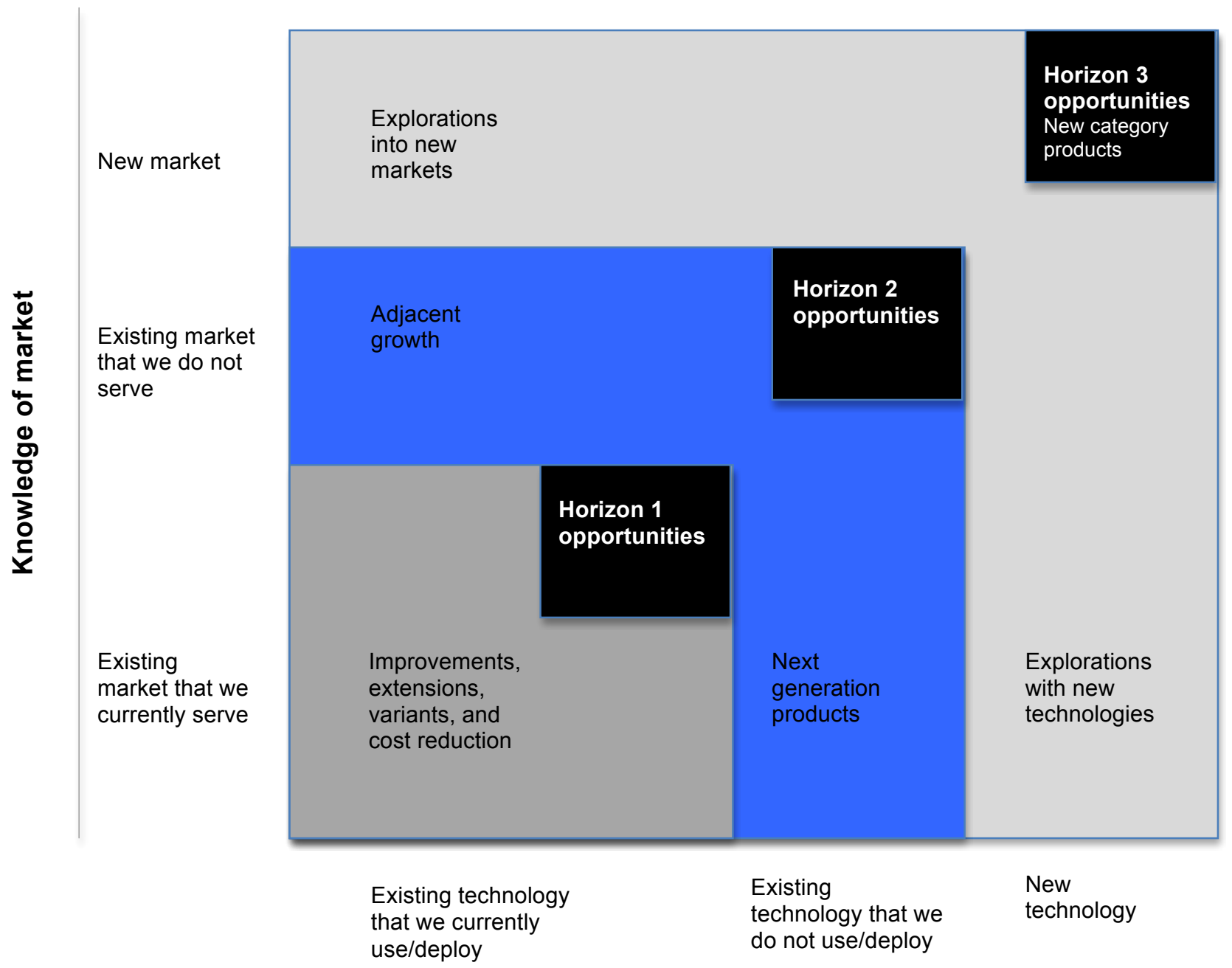

Figure 1: Horizon 2 opportunities are the focus for the Interdisciplinary Medical Product Development capstone course sequence.

\section{B. Fall Semester}

The starting point of the traditional senior design capstone sequence in Bioengineering at UIC is targeted at technical exploration. Some examples of project statement titles from current and past years are:

- Design a portable device to support body weight.

- Design a single use syringe.

- Design a device that will reduce the rate of hospital acquired infections using XYZ technology. 
This differs from the starting point of IMPD. For the IMPD course, the fall semester places emphasis is on identifying the problem, with focus on problem orientation and problem definition within the context of a needs analysis. These are the Project Activation, Problem Orientation and Problem Definition components of the Translational Innovation Process (see Figure 2). These include identification of constraints and objectives, and building a context of the project domain. Outputs from this phase of the project can include interview guides, trend analysis, identified important themes, key insights, inspirational products/ideas, detailed discussion of end-users (including user values), bibliography of primary research, interview transcription, process diagrams, description about the community of users, initial ideation/concept development, and a targeted problem brief.

Sample project statements from the past IMPD courses are:

- Create a product or service that extends CompanyXYZ's strength in (unnamed) systems into alternative health markets.

- How can CompanyXYZ help patients to administer their own health care within specified domains? (the domains were then specified for various demographics).

By design, these project statements are significantly broader in nature than the ones presenting in the traditional senior design course. This provides an opportunity for teams to conduct humancentered research to validate the problem and understand the underlying issues that contribute to the problem. In doing so, students gain a deeper appreciation for creating solutions that truly satisfy a need, which in turn, provides more possibility to apply novel approaches for truly innovative problem-solving.

Structurally, the 4 credit hour (per semester) course meets once a week for three hours with all faculty and students present, and includes the following activities throughout both semesters: an on-site visit to company/partner, weekly structured interactions with client mentors who work with an individual team for the year, presentations to client-partners during the midterm and final of each semester, weekly lectures, weekly studio sessions, weekly team meeting sessions outside of class time (one team meeting outside of class is required), workshops, and weekly or biweekly assignments that help develop the content for the client-partner presentations. The clientpartner owns all intellectual property generated in the class.

\section{Human-Centered Research Methods}

A design researcher leads several class sessions in the fall semester to introduce students to human-centered research methods, defined as "an integrated process that includes active consultation with people (users) through various means of primary research during all phases of design development"[13]. Through the course, students utilize these types of research methods and spend significant time identifying, discussing, classifying and prioritizing needs. Students are introduced to techniques from design research practitioners and/or faculty that address methodological approaches to observation, interviewing and synthesis of information. Some of the topics covered include (1) responsible conduct of research, including ethics of human subject research, (2) human-centered design research, (3) contextual inquiry and interviewing, (4) 
analysis and synthesis of research, and (5) prioritization of user needs. As the students collect data through their primary research, the faculty guides students to identify trends, understand underlying needs, and draw insightful connections between these needs and opportunities through in-class exercises and activities, and team assignments.



Students are instructed in the methodology of generative research within the process of humancentered design, which focuses on early stage understanding of stakeholder needs and values, including contextual observation and task flow analysis. Some activities related to generative research are detailed descriptions of process flow, physical space, documentation of verbal exchanges between clinicians and patients, and observations of non-verbal behavior and body language.

Generative research relies on ethnographic study, which in this case is an understanding of the context of the user and environment and their influence on medical devices that can satisfy previously unmet needs. Students are guided to observe at both the macro-level, including consideration for patient and clinician experience, sounds, and overall movement in the room, for 
example, and at the micro-level, related to instrument design and usage, depending on the project focus. A holistic view will help students understand the broader impact that device design can have on overall improved interactions, experiences and outcomes in these environments.

For most of the students, who are primarily undergraduates (although there are some first year medical students, and occasionally MFA Design graduate students and MBA students), this is a drastically different approach to problem solving than they have learned in previous classes, and perhaps more so for the bioengineering students. Usually, the subject matter of focus for a particular team's problem is new to all of the students, regardless of discipline, and substantial secondary research is required to familiarize themselves with the topic, associated terminology, and current related issues. Design researcher instructors guide students to design appropriate interview questions that result in meaningful information, such that time spent with clinicians is utilized as productively as possible. Teams then interview, shadow and observe physicians, surgeons and other clinicians in the College of Medicine at UIC and at the University of Illinois Hospital to gain context and firsthand information about the project statement.

\section{Team Dynamics}

The Bioengineering undergraduate program is designed so most students move through the curriculum in a cohort, sharing many of the same classes. Working with new students from other disciplines is invigorating, but not without its challenges. Faculty devote substantial effort to observing team dynamics and interpersonal communication, and intervene as necessary. As teams move through the innovation process, different disciplines are able to contribute in varying ways based on their skillset and knowledge base. Students complete peer and self-evaluations that are shared amongst the team twice per semester. These self and peer evaluations are used to measure Learning Outcome D: an ability to function on multi-disciplinary teams.

\section{$\underline{\text { Research Insights }}$}

Teams formally present their research findings to client mentors at midterm and end of the fall semester. In these presentations, they share an analysis of observed trends, important themes, key insights, inspirational products/ideas, detailed discussion of end-users, process diagrams, and description about the community of users. In addition, the team presents the market opportunity and key competitors that are operating in the same space. At the fall midterm, teams are directed to present their primary and secondary research findings, as well as how these findings informed any insights they identified to help them more deeply understand their project statement. These insights are critical for students to translate their research data into useful information for product development. Detailed feedback assessments provided by the three instructors as well as the client-partner is used to assess how well teams achieve Learning Outcome E: solving problems.

\section{Concept Generation}

The client partner provides feedback to further clarify or probe their findings. After this stage, teams progress further to ideation and concept development, based on their primary and secondary research and partner feedback. Teams then share these concept ideas with the end users for their input (either nurses or doctors or in some cases, patients). At the final fall 
presentation, teams present their concepts and rationale behind each concept to client mentors for feedback. Instructors and client mentors assess each team's ability to identify early concept designs to meet stated needs and constraints (Learning Outcome C), solving problems (Learning Outcome E), effectively communicate (Learning Outcome G), as well as whether they understand the true nature of the project statement based on their presentation (Learning Outcomes H and I).

\section{Grading}

While the midterm and final presentations are heavily factored into their final grade, assignments are designed to develop team knowledge in preparation for each presentation. Grade breakdowns are as follows:

$\begin{array}{ll}\text { Peer and self evaluations } & 20 \% \text { (midterm and final) } \\ \text { Assignments } & 15 \% \\ \text { Midterm Presentation } & 30 \% \\ \text { Final Presentation } & 30 \% \\ \text { In class participation } & 5 \%\end{array}$

Due to the non-disclosure agreement signed by all faculty and participants, work related to problem statements, presentations, and project work and their assessment is prevented from being shared in this paper.

\section{Spring Semester}

During the spring semester the emphasis moves into the solution space, where multiple solutions are explored through ideation, prototyping, iteration, evaluation (including clinical feedback), decision-making, market opportunity, testing, and product planning. Outputs from this phase typically include physical prototypes, technical drawings, marketing plans, project documentation, and concept visualization.

\section{Prioritization of Ideas}

Students end the first semester with ideation, and present a selected number of concepts to the client-partner. At the beginning of the spring semester, the students begin to take ownership in reducing the concepts to a single direction. In order to identify a singular project direction, the students must keep many considerations in mind and reach out to others for assistance in evaluating their ideas - they discuss their concepts with clinicians, client mentors, faculty, other students, and patients. All of these different stakeholders provide feedback on applicability, practicality, usefulness, and functionality. Clinical feedback is particularly important, and their input is solicited again as they refine their concepts down to a single solution. In addition, students use a Pugh matrix, a decision-making tool that helps guide the prioritization of ideas and concepts against the user needs. Teams are instructed to consider that client-partner feedback, clinician/user feedback, and decision matrices are all tools to help inform their refinement to a single concept, but none are definitive alone. The ability for students to identify and solve problems, Learning Outcome E, is evaluated both objectively and subjectively. Students are 
evaluated in how well they are able to create and use a decision matrix to evaluate how well their concepts address the problem provide to them at the beginning of the course. Subjective evaluation is done collectively by all three instructors, and considers how well they incorporate feedback provided by various stakeholders.

\section{Prototyping}

As teams begin developing concepts, students collaborate to develop prototypes with appropriate form, fit, feel and function. Iterative design, where students create physical prototypes of concepts throughout the design process, is a core aspect of this two-semester course sequence. Teams are guided to prototype various aspects of their design concepts in order to explore functionality, feasibility, as well as to create physical models with which to share with end-users to obtain feedback for continual concept refinement and improvement. Access to a dedicated machine shop and rapid prototyping equipment, such as laser cutters and 3D printers, at the Innovation Center allows student teams to prototype their design concepts quickly beginning in the early stages of design. However, low fidelity prototyping, using paper or foam-core, for example, is also strongly encouraged to get students comfortable with iteratively prototyping. Indeed, industrial design students are more familiar with the practice of early, rough prototyping but the engineering students initially hesitate to design before the concept is final. Design iteration, coupled with end-user feedback, are both aspects of an improved design process that abandons the silo-mentality of a staged method of product development, which focuses on sequential and separate steps in the process [14].

By utilizing an iterative design approach, students learn more about testing, both functional and against design criteria, throughout the process. Even though the prototypes represent different phases of the design process, manufacturing considerations, as well as regulatory and testing requirements, can be understood and addressed. Having a physical prototype to illustrate salient design features throughout the process significantly improves the quality of clinician feedback by visually communicating ideas and intent.

\section{$\underline{\text { Final Deliverables }}$}

Although the translational innovation process itself is emphasized over the final deliverable, teams spend the majority of the spring semester moving to refine their prototype and generating an accompanying marketing plan. The students present their final prototype (usually physical, except certain cases, such as an app, for example) and key items of the marketing plan, as well as deliver a Project Book, which serves as documentation of the entire process over the two semesters, to the client partner. The comprehensive project book includes primary and secondary research data, product requirements, technical drawings, marketing plan, and decision points and supporting rationale.

\section{Grading}

Similar to fall semester, the presentations are heavily weighted into their final grade; assignments are designed to develop team knowledge in preparation for each presentation. For the spring semester, the final project documentation book, a compilation of their work for the entire year as 
well as the final prototype, serves as deliverable to the client. Grade breakdowns are as follows:

$\begin{array}{ll}\text { Peer and self evaluations } & 15 \% \text { (midterm and final) } \\ \text { Assignments } & 25 \% \\ \text { Midterm Presentation } & 20 \% \\ \text { Final Presentation } & 20 \% \\ \text { Project Documentation } & 20 \%\end{array}$

\section{CHALLENGES AND COURSE ENHANCEMENTS}

As mentioned previously, a few of the deficiencies from the 2012-13 inaugural course were addressed during 2013-2014, which included: (1) establishing better relationships with the University of Illinois' medical campus in order to improve the understanding of the environment, (2) deepening the user-centered research approach in the course, and (3) securing participation of graphic design students to broaden the perspectives and skills of the teams.

In summer 2014, a Bioengineering Clinical Immersion program was offered to rising seniors enrolled in the IMPD senior design course. The program provides an opportunity for students to observe and interface with clinicians in their work environment so they can better understand engineering opportunities and requirements. Immersion experiences are important in permitting students to best practice human-centered design [2-6]. This six-week clinical immersion program is comprised of rotations within various clinical environments, including anesthesia, hematology/oncology, orthopedics, gastroenterology, ophthalmology, and transplant surgery, coupled with weekly lecture-discussions. During each rotation, a clinical mentor oversees the students, addresses questions and provide clarification on procedures, norms, and general commentary regarding process. In addition, the clinical mentors ensure that students accompany attending physicians on rounds within the clinic, alongside medical students. In this way, students are provided the opportunity to observe therapeutic treatment, as well as the considerations, concerns, and decisions brought forth through discussions between physicians, residents and medical students. Students who participate in the Clinical Immersion program and then enroll in IMPD courses have an advantage by understanding the value of human-centered research, and having established meaningful clinical connections already.

Some of the challenges encountered in the course serve to illustrate important issues related to interdisciplinary design work. In the first offering, the faculty realized terminology differed between disciplines - for example, the concept of a prototype. In general, engineers use the term to describe a three dimensional form of a design that serves to illustrate a feature or aspect of functionality, and define a model as a representation that predicts behavior. By this definition, an image or graphical representation can be considered a model. Industrial designers often use the term "prototype" to describe form, either two or three dimensional, whereby a sketch drawing can serve as a form of early prototype. In the class, the discrepancy is acknowledged.

In addition, students are able to conduct limited primary research focused on their project given the time constraints relative to the broadness of the initial project statement. Furthermore, HIPPA privacy considerations place restrictions on certain types of information obtained. Teams 
may only have a few oncologists from which to interview, for example, all of whom practice at a large, urban teaching hospital, which may not necessarily represent the breadth of the issue. While other IPD courses in the program (electrical engineering, computer science, mechanical engineering) often have a consumer end user, and can easily interview and observe 100 mobile phone users, for example, large data sets are impractical for clinical care settings. Substantial secondary research supplements the clinical interactions, and students are encouraged to reach out to personal contacts they may have with health care providers.

\section{CONCLUSION}

In the three years since it has been offered, this course has proven to be uniquely beneficial to students, particularly those who are interested in pursuing careers in medical device development. Based on student course evaluations, participants reported the following in Table 1 from Fall 2012 - Fall 2014 (five semesters). Students report great satisfaction with the course, and find it a challenging and valuable learning experience.

\begin{tabular}{|l|c|}
\hline \multicolumn{1}{|c|}{ COURSE EVALUATION } & $\begin{array}{c}\text { 1-5 } \\
\text { (lowest- highest) }\end{array}$ \\
\hline Overall quality of the course & 4.55 \\
\hline $\begin{array}{l}\text { You found the course intellectually challenging } \\
\text { and stimulating }\end{array}$ & 4.17 \\
\hline $\begin{array}{l}\text { You have learned something which you } \\
\text { consider valuable }\end{array}$ & 4.69 \\
\hline $\begin{array}{l}\text { Your interest in the subject has increased as a } \\
\text { result of this course }\end{array}$ & 4.50 \\
\hline
\end{tabular}

\section{Table 1: End of Semester Course Evaluation average ratings for Interdisciplinary Medical Product Development course (Fall 2012-Fall 2015)}

Given the limited number of spots available for this course (approximately ten per year), students must apply for enrollment consideration. This space limitation is due to the number of students from other disciplines that will also be in the course, so that it is appropriately balanced. The application includes a personal statement about how students believe this course will benefit them, as well as an in person interview. The first year offered, it was necessary to personally recruit potential students, but in the second and third years, there have been twice as many interested students as openings. The student interest in the course is due to positive "word of mouth" from previous participants about the experience in the course.

Furthermore, departmental exit surveys conducted prior to graduation indicate that IMPD participants find this one of their most valuable and personally rewarding courses. Students indicate that this course is often the focus of job interviews and is viewed very favorably by interviewers. In addition, three bioengineering students began working at CompanyXYZ Healthcare following participation in the course. 
Over the past few years, it has been challenging to offer students a rich experience within the healthcare domain, but through the process we have learned a few things that apply on a broader level, and hope to build on these moving forward:

(A) We seek to provide interaction with many types of clinical end users. IMPD aims to provide interaction with a variety of clinical end users to inform the design process through extended exposure to clinical environments. Gaining first-hand knowledge of these many users within these medical environments is very difficult because of: patient confidentiality, the time constraints of clinicians, and the coordination of so many different schedules. It is important to understand the priorities and perspectives of each type of stakeholder with a typical project negotiating the needs of doctors, nurses, technicians, patients, purchasers, and regulatory constraints/considerations. The domain of health care / health design is different from consumer product development, and more complex.

(B) We seek to provide an immersive clinical experience. UIC is uniquely situated for its ability to provide a strong and meaningful clinical immersion experience. First-hand exposure to clinical environments provides a holistic view that will help students understand the broader impact that design can have on improved interactions, experiences, devices and ultimately medical outcomes. And it is only through this deep knowledge of the environment that they can frame (or re-frame) complex design problems to approach and solve them in innovative ways. The Bioengineering Clinical Immersion Program during the summer prior to IMPD is offered to students, where they can expand and deepen their knowledge of these environments. Observations of the clinical environments and understanding of end-user needs (doctors, nurses, technicians, patients) are critical for successful design, and the broader impact that device design can have on overall improved efficiency in the health care workplace is an important aspect of the bioengineering field. The insight gained through an academic and student perspective is valuable for our client-partners as well, and has led to a committed clientpartner relationship - UIC and CompanyXYZ Healthcare have partnered in 2012-13, 2013-14, and 2014-15.

(C) We seek to provide good learning experiences for all disciplines. Lastly, it is important to think about the unique contributions from the various disciplines. Since this collaboration is somewhat new and still evolving, we are only at the beginning of understanding the complex landscape of the individual disciplinary contributions versus the collective (what they can do apart-versus- what they are capable of together). We hope to be able to further articulate this in future work.

In summary, this paper describes an innovative interdisciplinary medical product development course that is comprised of students and faculty from bioengineering, industrial design, marketing and medicine. This course provides students an opportunity to work on a problem posed by an industry partner that is of strategic business interest; as such, all students must agree to sign a non-disclosure agreement prior to enrolling in the course. The Interdisciplinary Medical Product Development course represents real world scenarios in which multiple disciplines work together during product development with a shared end goal. Over the three 
years this course has been offered, we have continually enhanced the curriculum to best address the desired course learning outcomes, and provide value to the client-partner, i.e. inclusion of medical student in the course, and offering a summer clinical immersion internship for bioengineering students prior to enrollment in IMPD. The IMPD course prepares bioengineering students for industry, by enhancing students' abilities to understand the medical product development process from needs identification to iterative prototyping, effectively convey detailed and technical information to both engineers and non-technical stakeholders, understand the varying perspectives of other disciplines, and emphasizing the importance of user-centered research to validate the problem and solicit clinical end-user feedback throughout the product development process.

[1] Ulrich, Karl T and Steven D. Eppinger. "Educating Product Development Leaders," Design Management Journal, 3(3), 47-54, Summer 1992.

[2] N. Hotaling, B. B. Fasse, L. F. Bost, C. D. Hermann, and C. R. Forest, "A Quantitative Analysis of the Effects of a Multidisciplinary Engineering Capstone Design Course," Journal of Engineering Education, 101(4), 630-656, 2012.

[3] J. T. Allenstein, B. Rhoads, P. Rogers, and C. A. Whitfield, "Examining the Impacts of a Multidisciplinary Engineering Capstone Design,” 120th ASEE Annual Conference and Exposition, Atlanta, GA, 2013

[4] "Medical Devices.“ http://ceas.uc.edu/special_programs/MedDev.html; Accessed 3/28/15.

[5] "NUvention: Medical.” http://fcei.northwestern.edu/curriculum/nuvention/medical.html; Accessed 3/28/15.

[6] U.S. Food and Drug Administration. How Human Factors Lead to Medical Device Adverse Events. http://www.fda.gov/MedicalDevices/Safety/AlertsandNotices/Tipsand ArticlesonDeviceSafety/ucm070185.htm; Accessed 4/28/13.

[7] Zoltowski, Carla B., William C. Oakes, and Monica E. Cardella. "Students' Ways of Experiencing HumanCentered Design,” Journal of Engineering Education,” 101(1), 28-59, 2012.

[8] Money, Arthur G, Julie Barnett, Jasna Kuljis, Michael P Craven, Jennifer L Martin, and Terry Young. "The Role of the User Within the Medical Device Design and Development Process: Medical Device Manufacturer's Perspectives,” BMC Medical Informatics and Decision Making, 11(15), 587-634, 2001.

[9] Privitera, Mary Beth, M. Design and Dale, L. Murray. "Applied Ergonomics: Determining User Needs in Medical Device Design," in 31st Annual International Conference of the IEEE EMBS, Minneapolis, MN, 2009.

[10] Maguire, Martin. "Methods to Support Human-Centered Design," International Journal of Human-Computer Studies, 55(4), 587-634, 2001.

[11] Gertner, Michael. "Biomedical Innovation, Surgical Innovation, and Beyond," in 9th Annual National Collegiate Inventors and Innovators, San Diego, CA, 2005. 
[12] Human factors engineering - design of medical devices. ANSI/AAMI Standard HE75, 2009.

[13] Hanington, Bruce M. "Relevant and Rigorous: Human-Centered Research and Design Education," Design Issues: 26(3), Summer, Massachusetts Institute of Technology (C 2010

[14] Yassine, Ali and Dan Braha. "Complex Concurrent Engineering and the Design Structure Matrix Method," Concurrent Engineering, 11(3), 165-176, 2003. 